\title{
Magnetic resonance imaging analysis of rotator cuff tear after shoulder dislocation in a patient older than 40 years
}

\author{
Jung-Han Kim ${ }^{1}$, Jin-Woo Park ${ }^{2}$, Si-Young Heo ${ }^{3}$, Young-Min Noh ${ }^{3}$ \\ ${ }^{1}$ Department of Orthopedic Surgery, Inje University Busan Paik Hospital, Inje University College of Medicine, Busan, Korea \\ ${ }^{2}$ Department of Orthopedic Surgery, Gimhae-Sarang Hospital, Gimhae, Korea \\ ${ }^{3}$ Department of Orthopedic Surgery, Dong-A University Hospital, Dong-A University College of Medicine, Busan, Korea
}

\begin{abstract}
Background: This study was designed to evaluate characters of the rotator cuff tear (RCT) recognized after primary shoulder dislocation in patients older than 40 .

Methods: From 2008 to 2019, patients who visited two hospitals after dislocation were retrospectively reviewed. Inclusion criteria were patients over 40 who had dislocation, with magnetic resonance imaging (MRI) undergone. Exclusion criteria were patients who lost to follow-up, combined with any proximal humerus fracture, brachial plexus injury, and previous operation or dislocation history in the ipsilateral shoulder. Also patients who had only bankart or bony bakart lesion in MRI were excluded. We evaluated RCTs that were recognized by MRI after the primary shoulder dislocation with regard to tear size, degree, involved tendons, fatty degeneration, the age when the first dislocation occurred, and the duration until the MRI was evaluated after the dislocation.

Results: Fifty-five RCTs were included. According to age groups, the tear size was increased in coronal and sagittal direction, the number of involved tendons was increased, and the degree of fatty degeneration was advanced in infraspinatus muscle. Thirty-two cases (58.2\%) conducted MRI after 3 weeks from the first shoulder dislocation event. This group showed that the retraction size of the coronal plane was increased significantly and the fatty accumulation of the supraspinatus muscle had progressed significantly.

Conclusions: Age is also a strong factor to affect the feature of RCT after the shoulder dislocation in patients over 40. And the delay of the MRI may deteriorate the degree of tear size and fatty degeneration.
\end{abstract}

Keywords: Dislocation; Magnetic resonance imaging; Rotator cuff; Fatty degeneration; Prognosis

\section{INTRODUCTION}

The prevalence of traumatic anterior shoulder dislocation in the elderly has increased due to recent changes in lifestyle and life expectancy [1]. Recurrent instability is the main problem after shoulder dislocation in young patients, while rotator cuff tear is more common in the elderly [2,3]. However, immediate diagnosis of pathology is very difficult because most patients visit and present via the emergency room and may not undergo further evaluation. Revisiting the clinic after reduction is relatively un-

Received: August 4, $2020 \quad$ Revised: August 16, $2020 \quad$ Accepted: August 19, 2020

Correspondence to: Young-Min Noh

Department of Orthopedic Surgery, Dong-A University Hospital, Dong-A University College of Medicine, 26 Daesingongwon-ro, Seo-gu, Busan 49201, Korea

Tel: +82-51-240-5166, Fax: +82-51-254-6757, E mail: thugdoc77@dau.ac.kr, ORCID: https://orcid.org/0000-0001-7149-7526

Financial support: None.

Conflict of interest: None.

Copyright(C) 2020 Korean Shoulder and Elbow Society. All Rights Reserved.

This is an Open Access article distributed under the terms of the Creative Commons Attribution Non-Commercial License (http://creativecommons.org/licenses/by-nc/4.0/) which permits unrestricted non-commercial use, distribution, and reproduction in any medium, provided the original work is properly cited. 
common especially for elderly patients, and it is currently debated whether magnetic resonance imaging (MRI) should be performed within in a short time period after the first dislocation [2,4-6].

It is unclear whether shoulder dislocation triggers rotator cuff tear or whether an asymptomatic, pre-existing rotator cuff tear induces imbalanced shoulder movement, resulting in shoulder dislocation with minor trauma [7,8]. In older patients, it is difficult to distinguish the acute and chronic features of rotator cuff tear that are recognized after primary shoulder dislocation. It is also uncertain whether delay of the diagnosis contributes to adverse outcomes and prognosis $[4,5,9,10]$. MRI is regarded as the most accurate diagnostic modality to detect rotator cuff tear and for estimating tear degree and tissue quality $[6,11,12]$.

About $60 \%$ of nontraumatic rotator cuff tears remain asymptomatic for years [13-15], while most cases develop the first symptoms after significant trauma. One study reported significantly higher prevalence of rotator cuff tear after trauma compared to a control group without trauma [16]. Thus, it must be determined whether shoulder dislocation truly causes rotator cuff tear or if patients with an asymptomatic rotator cuff tear are exacerbated by a single dislocation event $[9,17]$. Although some studies suggest a number of symptoms to distinguish between solely traumatic and purely degenerative rotator cuff tear, such as patient medical history, physical examination, and imaging modalities [18,19], these factors are insufficient for complete differentiation and lack evidence-based data. This study was designed to evaluate characteristics of rotator cuff tear using MRI to recognize incidents after primary shoulder dislocation in patients older than 40 years.

\section{METHODS}

This study was approved by the Institutional Review Board of Inje University Busan Paik Hospital (No. 20-0054).

Seventy-four patients older than 40 years who presented for treatment of traumatic anterior dislocation of the shoulder from 2008 to 2019 were retrospectively reviewed. Of these patients, three were lost to follow-up. Eight patients with proximal humerus fracture, brachial plexus injury, previous shoulder operation, or dislocation history in the ipsilateral shoulder were excluded. Another eight patients were excluded because they had only Bankart or bony Bankart lesion on MRI. Therefore, a total of 55 patients was enrolled in this study.

Demographic data were obtained through chart review. All rotator cuff tears were confirmed by MRI after the dislocation event. MRI was performed at two imaging centers using a 1.5- or
3.0-T imaging unit (Sigma; GE Medical Systems, Milwaukee, WI, USA) equipped with a dedicated shoulder coil. A standardized imaging protocol was used according to hospital parameters, but two of the protocols did not align. The following MRI sequences were included for review: fat-suppressed T1-weighted fast spin echo sequences in the axial and oblique coronal planes parallel to the long axis of the supraspinatus tendon and the oblique sagittal plane perpendicular to the long axis of the supraspinatus tendon. Images were acquired with a slice thickness of $3 \mathrm{~mm}$ and an interslice gap with a $1 \mathrm{~mm}$ field of view of $16 \times 16 \mathrm{~cm}$. Images were interpreted using a standard picture archiving and communication system (PACS) workstation (Centricity, GE Medical Systems). All MRI findings were interpreted by two board-certified orthopedic surgeons (JHK, YMN) who confirmed the degree of fatty infiltration and tear size. Two weeks later, the procedure was repeated for validation (Table 1 ).

A tear was defined as a discontinuity of tendon fibers with the gap showing a high T2 signal [20-22]. A full-thickness tear was defined as a high signal extending through the depth of the tendon. The tear was measured in two planes (anterior to posterior [AP] and medial to lateral $[\mathrm{ML}])$ on the full-thickness supraspinatus or infraspinatus muscle.

Fatty infiltration was graded on a scale from 0 to 4 as a modification of the classification of Goutallier et al. [23]. It was adapted to MRI: grade 0 means no fatty deposits; grade 1, some fatty streaks; grade 2 , more muscle than fat; grade 3 , fat equal to muscle; and grade 4, more fat than muscle.

To evaluate the effect of delayed MRI after the first injury event, we divided patients into two groups based on time from injury to MRI evaluation. The first group (group I) waited less than 3 weeks after dislocation, while group II was evaluated more than 3 weeks after dislocation. Three weeks was used as the cutoff based on previous clinical reports [4,24].

Table 1. Overall patient data

\begin{tabular}{lc}
\hline Variable & Value \\
\hline Number & 55 \\
Age (yr) & $61.2 \pm 11.5(40-82)$ \\
Sex (male:female) & $34: 21$ \\
Follow-up period (mo) & $48.7 \pm 36.6(12-115)$ \\
Duration (wk) & $17.1 \pm 21.4(1-96)$ \\
Fatty degeneration grade & \\
$\quad$ Supraspinatus muscle & $1.71 \pm 1.12$ \\
$\quad$ Infraspinatus muscle & $1.33 \pm 1.11$ \\
Subscapularis muscle & $1.04 \pm 0.83$ \\
Teres minor muscle & $0.20 \pm 0.48$ \\
\hline
\end{tabular}

Values are presented as mean \pm standard deviation (range) or mean \pm standard deviation. 
Comparative statistics were performed using Student t-test, chi-square test, or Fisher's exact test (IBM SPSS ver. 19; IBM Corp., Armonk, NY, USA). The level of significance was set at $\mathrm{P}<0.05$. Data are presented as mean \pm standard deviation.

\section{RESULTS}

Fifty-five rotator cuff tears were recognized on MRI after the first anterior dislocation of the shoulder. The average follow-up period was $48.7 \pm 38.6$ months (range, $12-115$ months). The age of the patients at the time of primary shoulder dislocation was $61.2 \pm 11.5$ years (range, $40-82$ years). There were 21 women with a mean age of $64.5 \pm 10.2$ years and 34 men with a mean age of $59.2 \pm 10.9$ years. The mean duration between primary shoulder dislocation and MRI evaluation was $17.1 \pm 21.4$ weeks (range, 1-96 weeks). The mean degree of fatty degeneration was 1.71 in the supraspinatus muscle, 1.33 in the infraspinatus muscle, 1.04 in the subscapularis muscle, and 0.20 in the teres minor muscle (Table 1).

Of the 55 shoulders, 26 (47.3\%) had isolated rotator cuff tear ( $R$ group) and 29 (52.7\%) had combined Bankart lesion with rotator cuff tear ( $\mathrm{B}+\mathrm{R}$ group). The mean age was $69.12 \pm 8.84$ years in the $\mathrm{R}$ group and $61.14 \pm 10.52$ years in the $\mathrm{B}+\mathrm{R}$ group, a significant difference. The mean tear size in the sagittal and coronal planes in the R group was $31.12 \pm 8.57 \mathrm{~mm}$ and $30.81 \pm 8.60 \mathrm{~mm}$, respectively. The $\mathrm{R}$ group had significantly longer tear size in both directions compared with the $\mathrm{B}+\mathrm{R}$ group $(16.61 \pm 12.80 \mathrm{~mm}$ and $16.93 \pm 12.32 \mathrm{~mm}$, respectively). The number of cases in the $\mathrm{R}$ group with more than two injured tendons was 26 (100\%) and the number of cases that involved a long head of the biceps tendon lesion was $22(84.6 \%)$. The degree of fatty degeneration of the rotator cuff was significantly different between the two groups, with exception of the teres minor muscle (Fig. 1). These findings are summarized in (Table 2).

Age and tear size in both directions were positively correlated (Pearson's correlation coefficient 0.476 in the AP direction and 0.452 in the ML direction) (Fig. 2). The older age group showed significant increase in tear size, number of injured tendons, and long head biceps tendon lesions (Table 3). Interestingly, degree of

Table 2. Comparison of age, tear size, number of injured tendons, and accompanying injuries between two groups

\begin{tabular}{lccc}
\hline Variable & B+R group & R group & P-value \\
\hline Number & $29(52.7)$ & $26(47.3)$ & \\
Age (yr) & $61.12 \pm 10.52$ & $69.12 \pm 8.84$ & 0.000 \\
Tear size (mm) & & & \\
$\quad$ AP & $16.61 \pm 12.80$ & $31.12 \pm 8.57$ & 0.000 \\
$\quad$ ML & $16.93 \pm 12.32$ & $30.81 \pm 8.60$ & 0.000 \\
No. of injured tendons & & & 0.005 \\
$\quad$ (SS) & 8 & 0 & \\
$\quad \geq 2$ (SS+IS) & 21 & 26 & \\
Accompanying injury & & & \\
$\quad$ LHBT lesion & 15 & 22 & 0.011 \\
Labral tear & 25 & 0 & 0.000 \\
Hill Sachs lesion & 22 & 20 & 0.926 \\
\hline
\end{tabular}

Values are presented as number (\%) or mean \pm standard deviation. $\mathrm{B}+\mathrm{R}$ group: rotator cuff tear combined with labral tear group, R group: rotator cuff tear group.

AP: anterior to posterior, ML: medial to lateral, SS: supraspinatus, IS: infraspinatus, LHBT: long head of the biceps tendon.

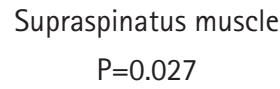

$P=0.027$

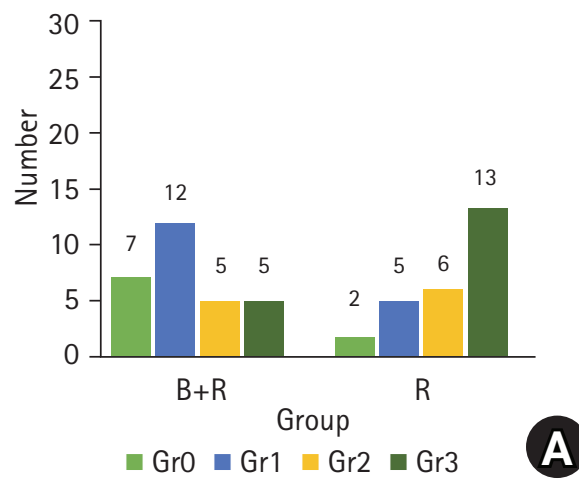

Infraspinatus muscle

$P=0.002$
Subscapularis muscle

$\mathrm{P}=0.814$

Fig. 1. Distribution of degree of fatty degeneration of the supraspinatus muscle (A), infraspinatus muscle (B), and subscapularis muscle (C) between the $B+R$ and $R$ groups. The results indicate significant differences for these muscles. $B+R$ group: rotator cuff tear combined with labral tear group, R group: rotator cuff tear group, Grade $(\mathrm{Gr}) 0$ : no fatty deposits, Gr1: some fatty streaks, Gr2: more muscle than fat, Gr3: fat equal to muscle. 

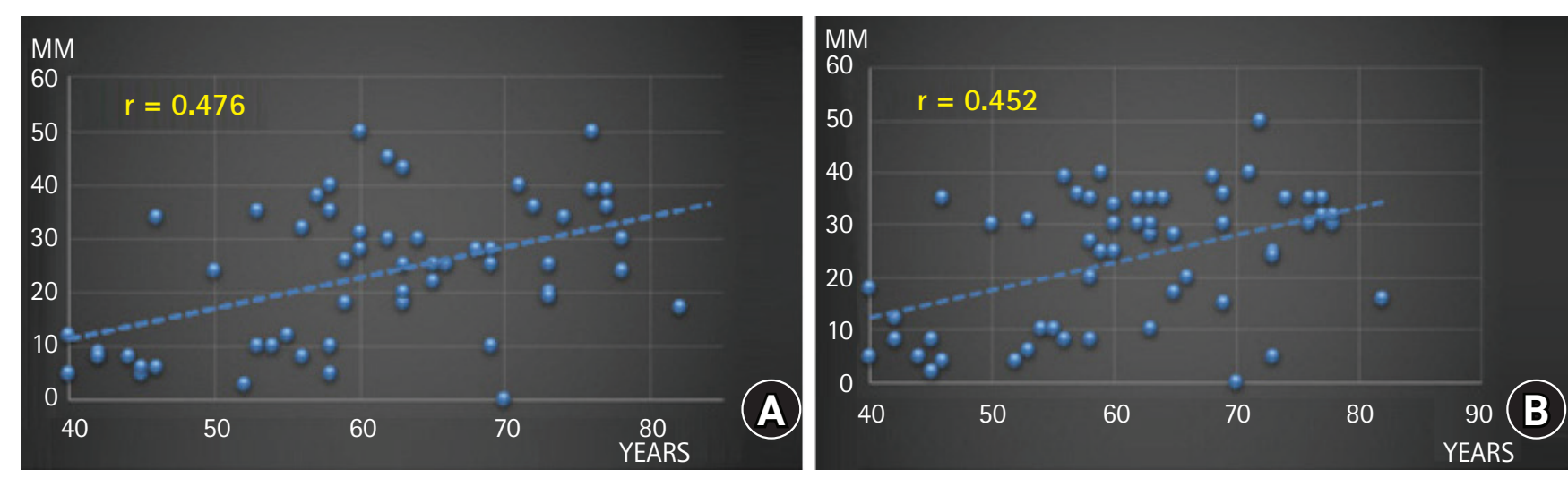

Fig. 2. Distribution of tear size from anterior to posterior direction (A) and medial to posterior direction (B) as age increases. Both directions showed positive correlation.
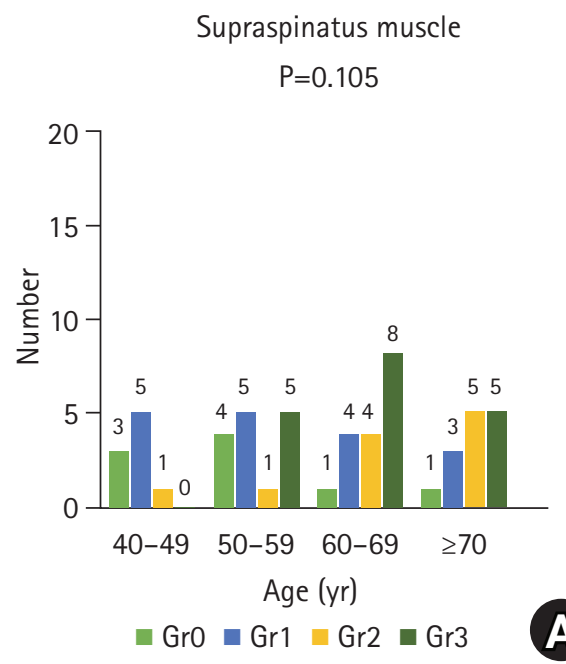

Infraspinatus muscle

$$
P=0.019
$$

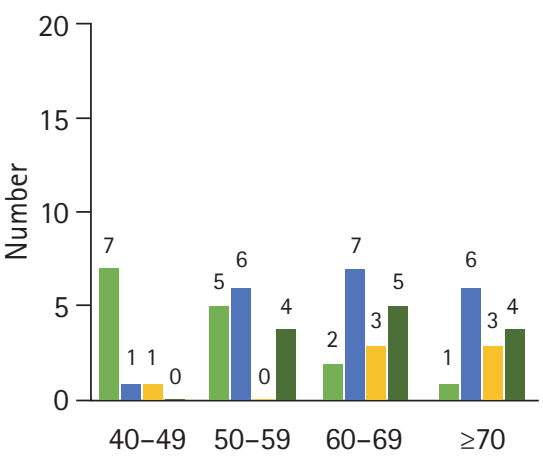

Age (yr)

$\square \mathrm{Gr}=\mathrm{Gr} 1-\mathrm{Gr} 2 \square \mathrm{Gr} 3$
Subscapularis muscle

$\mathrm{P}=0.600$

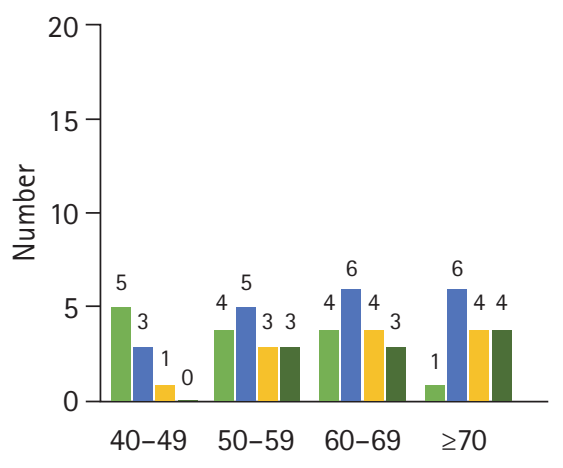

Age (yr)

$\square \mathrm{Gr} 0 \mathrm{Gr} 1 \square \mathrm{Gr} 2 \square \mathrm{Gr} 3$

Fig. 3. Distribution of fatty degeneration grade in the supraspinatus muscle (A), infraspinatus muscle (B), and subscapularis muscle (C) according to age group. Degree of fatty degeneration showed a significant difference in the infraspinatus muscle. Grade (Gr)0: no fatty deposits, Gr1: some fatty streaks, Gr2: more muscle than fat, Gr3: fat equal to muscle.

Table 3. Comparison of tear size, number of injured tendons, and accompanying injuries according to age group

\begin{tabular}{|c|c|c|c|c|c|}
\hline Variable & $40-49$ yr & $50-59 \mathrm{yr}$ & $60-69 \mathrm{yr}$ & $\geq 70 \mathrm{yr}$ & P-value \\
\hline Number & $9(16.4)$ & $15(27.3)$ & $17(30.9)$ & $14(25.4)$ & \\
\hline \multicolumn{6}{|l|}{ Tear size $(\mathrm{mm})$} \\
\hline $\mathrm{AP}$ & $10.30 \pm 9.16$ & $20.40 \pm 13.08$ & $28.41 \pm 9.91$ & $29.21 \pm 12.69$ & 0.001 \\
\hline ML & $10.78 \pm 10.28$ & $21.93 \pm 13.15$ & $28.06 \pm 8.18$ & $27.79 \pm 13.29$ & 0.003 \\
\hline No. of injured tendons & & & & & 0.016 \\
\hline 1 & 4 & 3 & 0 & 1 & \\
\hline$\geq 2$ & 5 & 12 & 17 & 13 & \\
\hline \multicolumn{6}{|l|}{ Accompanying injury } \\
\hline LHBT lesion & 3 & 8 & 14 & 12 & 0.019 \\
\hline Labral tear & 8 & 10 & 4 & 3 & 0.001 \\
\hline Hill Sachs lesion & 8 & 12 & 10 & 12 & 0.215 \\
\hline
\end{tabular}

Values are presented as number (\%) or mean \pm standard deviation.

AP: anterior to posterior, ML: medial to lateral, LHBT: long head of the biceps tendon. 
fatty degeneration is advanced with age only in the infraspinatus muscle (Fig. 3).

When shoulders were divided into two groups by a 3-week duration between the first dislocation event and the MRI procedure, $23(41.8 \%)$ were evaluated within 3 weeks after injury and 32 shoulders (58.2\%) were evaluated after more than 3 weeks. There was no difference between the two groups in age, number of injured tendons, or associated lesions.

However, retraction size of the coronal plane was increased and fatty accumulation of the supraspinatus muscle was more advanced in group I (less than 3 weeks) than group II (more than 3 weeks) (Table 4, Fig. 4).

\section{DISCUSSION}

In this study, we focused on rotator cuff tear recognized on MRI after a dislocation event. As age progresses, the rotator cuff weakens and is more prone to tearing $[25,26]$. The results of this study indicate that age is a strong factor of tear size, number of involved tendons, and fatty degeneration of the infraspinatus muscle in primary shoulder dislocation in patients older than 40 years. It is apparent that fatty degeneration and tear progression progress in the AP direction (from supraspinatus to infraspinatus) because the degree of fatty degeneration was significantly different in the infraspinatus muscle in the older age group. Because the infraspinatus muscle is the main depressor of the humeral head, dysfunction results in upward migration of the humerus with subacromial impingement and loss of strength in external rotation and elevation $[27,28]$. We assumed that it is paramount to recog- nize rapid fatty infiltration of the Infraspinatus to avoid poor outcomes after cuff repair in patients older than 40 years, particularly for those with shoulder dislocation of fatty infiltration grade 2 or higher [29].

The rotator cuff significantly contributes to the stability of the glenohumeral joint, especially in elderly patients. It is possible that the higher prevalence of pre-existing rotator cuff disease in older patients may lead to abnormal glenohumeral motion and predispose an older individual to shoulder instability with low-energy trauma $[7,30]$. Hsu et al. [30] showed in a cadaver

Table 4. Comparison of age, tear size, number of injured tendons, and accompanying injuries according to duration from injury to MRI

\begin{tabular}{lccc}
\hline \multirow{2}{*}{ Variable } & \multicolumn{2}{c}{ Duration (wk) } & \multirow{2}{*}{ P-value } \\
\cline { 2 - 3 } & $0-3$ & $\geq 3$ & \\
\hline Number & $23(41.8)$ & $32(58.2)$ & \\
Age (yr) & $62.87 \pm 11.61$ & $60.03 \pm 10.65$ & 0.352 \\
Tear size (mm) & & & \\
$\quad$ AP & $20.52 \pm 13.79$ & $25.58 \pm 12.42$ & 0.160 \\
$\quad$ ML & $19.09 \pm 11.62$ & $26.66 \pm 12.70$ & 0.028 \\
No. of injured tendons & & & 0.120 \\
$\quad 1$ & 1 & 7 & \\
$\quad 22$ & & 25 & \\
Accompanying injury & & & \\
$\quad$ LHBT lesion & 14 & 23 & 0.391 \\
$\quad$ Labral tear & 12 & 13 & 0.396 \\
$\quad$ Hill Sachs lesion & 15 & 27 & 0.099 \\
\hline
\end{tabular}

Values are presented as number (\%) or mean \pm standard deviation. MRI: magnetic resonance imaging, AP: anterior to posterior, ML: medial to lateral, LHBT: long head of the biceps tendon.
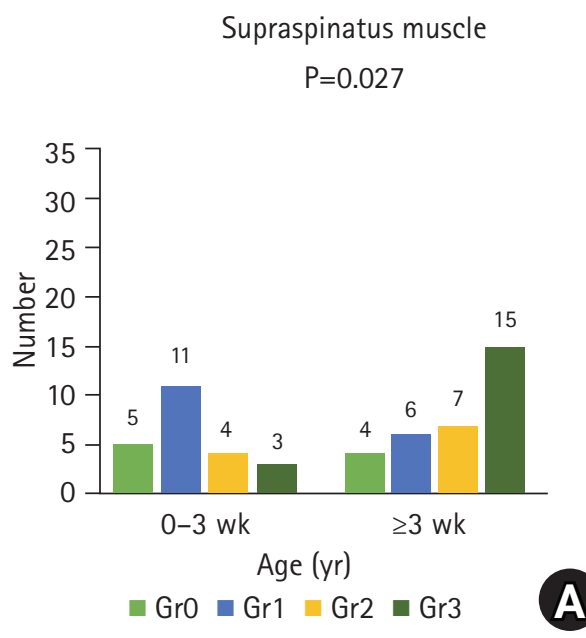

Infraspinatus muscle $P=0.164$

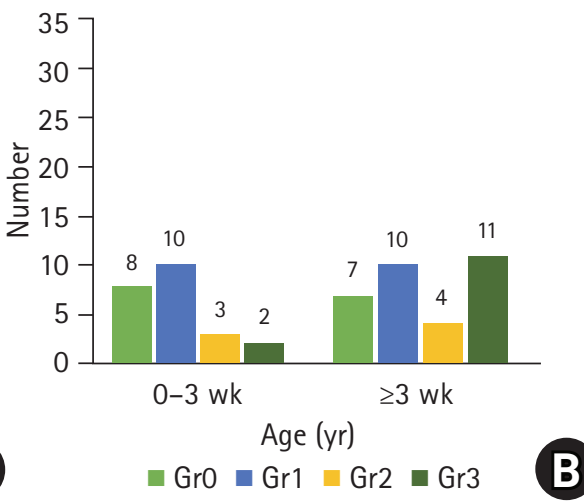

Subscapularis muscle $\mathrm{P}=0.479$

Fig. 4. Distribution of fatty degeneration grade in the supraspinatus muscle (A), infraspinatus muscle (B), and subscapularis muscle (C) according to duration from injury to magnetic resonance imaging. Degree of fatty degeneration showed a significant difference in the supraspinatus muscle. Grade (Gr)0: no fatty deposits, Gr1: some fatty streaks, Gr2: more muscle than fat, Gr3: fat equal to muscle. 
model that rotator cuff tear resulted in abnormal glenohumeral translation, and that larger tears had a greater tendency for direct anterior translation. Pouliart and Gagey [31] showed that the humeral head dislocates in the presence of less extensive capsuloligamentous lesions when rotator cuff lesions are present. Increased age, advanced fatty infiltration, and longer tear size might have weakened the posterior structures and resulted in anterior dislocation without anteroinferior labral lesion, such as Bankart lesion in the elderly. These characteristics are also shown in our results, which indicated that the rotator cuff tear group ( $\mathrm{R}$ group) was statistically much older than the rotator cuff combined with labral tear group ( $\mathrm{B}+\mathrm{R}$ group). The $\mathrm{R}$ group cases all involved an infraspinatus tear, while infraspinatus tear involvement was present in about $72.4 \%$ of the BR group. These results suggest that shoulder dislocation without labral tear is strongly related with infraspinatus tear in elderly patients and is referred to as the posterior shoulder dislocation mechanism [7,30,31]. In our results, fatty degeneration of the subscapularis was not statistically different according to age or between the $\mathrm{R}$ and $\mathrm{B}+\mathrm{R}$ groups.

Delayed diagnosis of rotator cuff tear after dislocation may decrease the recovery potential. Previous studies [4,24] reported that patients who experienced acute injury with severe compromise of shoulder function that could be due to the rotator cuff tear should be diagnosed using further evaluations, and that surgical repair of rotator cuff tear should be performed within 3 weeks of injury to achieve the best surgical results. Failure to meet the conservative 3 -week treatment window after primary dislocation in older patients and persistence of significant pain or weakness are indications for further investigation [32,33]. Another study showed that infraspinatus fatty infiltration increased significantly when multiple tendons were torn, and that surgical repair should be performed before stage 2 fatty infiltration in older patients [34].

We hypothesized that rotator cuff tear identified by MRI after 3 weeks from dislocation may have features different from those of tear identified earlier. Based on our results, coronal tear size and degree of fatty infiltration in the supraspinatus muscle were increased significantly in the group with more than 3 weeks before intervention (Table 4, Fig. 4). These results suggest that shoulder dislocation may worsen the course of degeneration even in the early period of post-dislocation in elderly patients. These results also provide a theoretical background for understanding why rapid rotator cuff repair might be considered in acute shoulder dislocation due to the tendency of rapid fatty progression in elderly patients. Previous studies have reported inferior clinical results after delayed treatment of traumatic rotator cuff tear, which is likely due to loss of elasticity in tendons and the signifi- cantly increased tension of the repair. Increased tension is related to decreased viscoelastic properties of the tendons and poor rotator cuff healing [24,35]. In a rat model, supraspinatus tendon detachment resulted in rapid loss of muscle mass by 1 week after injury [36,37]. In biomechanical studies, tension at the repaired tendon progressively increased with time from injury because of increase in retraction of the musculotendinous unit and in stiffness of the muscle and tendon $[38,39]$. Unfortunately, we could not evaluate clinical outcomes according to duration and so assumed that delayed diagnosis and treatment may have adverse effects on clinical outcomes based on our results and previous studies.

This study had several limitations; in particular, the relatively small number of cases and their retrospective enrollment. This study could not distinguish between acute lesion and chronic lesion of the rotator cuff, and there were no clinical outcomes to evaluate function, satisfaction, or additional dislocation in patients because of difficulty with long-term follow-up. We also did not have a uniform MRI protocol because the MRI studies were conducted at different institutions and during different timeframes from 2008 to 2019. However, we do not believe that such differences compromised our ability to analyze fatty infiltration.

We concluded that tear size of the rotator cuff and fatty infiltration of the infraspinatus muscle are positively correlated with age in primary shoulder dislocation in patients older than 40 years. Combined Bankart lesion is more frequently observed in younger patients. Tear size (ML) of the rotator cuff and fatty infiltration of the supraspinatus may advance faster after dislocation in this age group, and careful attention, diagnosis, and follow-up are important for optimizing patient outcomes.

\section{ORCID}

Jung-Han Kim

https://orcid.org/0000-0002-6201-5895

Jin-Woo Park

https://orcid.org/0000-0001-6506-3027

Si-Young Heo

https://orcid.org/0000-0002-7452-4136

Young-Min Noh

https://orcid.org/0000-0001-7149-7526

\section{REFERENCES}
1. Maier M, Geiger EV, Ilius C, Frank J, Marzi I. Midterm results after operatively stabilised shoulder dislocations in elderly pa- tients. Int Orthop 2009;33:719-23.
2. Hovelius L, Eriksson K, Fredin H, et al. Recurrences after initial dislocation of the shoulder: results of a prospective study of treatment. J Bone Joint Surg Am 1983;65:343-9.
3. Pevny T, Hunter RE, Freeman JR. Primary traumatic anterior 
shoulder dislocation in patients 40 years of age and older. Arthroscopy 1998;14:289-94.

4. Bassett RW, Cofield RH. Acute tears of the rotator cuff: the timing of surgical repair. Clin Orthop Relat Res 1983;(175):18-24.

5. Braune C, von Eisenhart-Rothe R, Welsch F, Teufel M, Jaeger A. Mid-term results and quantitative comparison of postoperative shoulder function in traumatic and non-traumatic rotator cuff tears. Arch Orthop Trauma Surg 2003;123:419-24.

6. Dinnes J, Loveman E, McIntyre L, Waugh N. The effectiveness of diagnostic tests for the assessment of shoulder pain due to soft tissue disorders: a systematic review. In: NIHR health technology assessment programme: executive summaries. Southampton: NIHR Journals Library; 2003.

7. Loehr JF, Helmig P, Søjbjerg JO, Jung A. Shoulder instability caused by rotator cuff lesions: an in vitro study. Clin Orthop Relat Res 1994;(304):84-90.

8. Porcellini G, Paladini P, Campi F, Paganelli M. Shoulder instability and related rotator cuff tears: arthroscopic findings and treatment in patients aged 40 to 60 years. Arthroscopy 2006; 22:270-6.

9. Neviaser RJ, Neviaser TJ, Neviaser JS. Anterior dislocation of the shoulder and rotator cuff rupture. Clin Orthop Relat Res 1993;(291):103-6.

10. Neviaser RJ, Neviaser TJ. Recurrent instability of the shoulder after age 40. J Shoulder Elbow Surg 1995;4:416-8.

11. Dwyer T, Razmjou H, Henry P, Gosselin-Fournier S, Holtby R. Association between pre-operative magnetic resonance imaging and reparability of large and massive rotator cuff tears. Knee Surg Sports Traumatol Arthrosc 2015;23:415-22.

12. Fuchs B, Weishaupt D, Zanetti M, Hodler J, Gerber C. Fatty degeneration of the muscles of the rotator cuff: assessment by computed tomography versus magnetic resonance imaging. J Shoulder Elbow Surg 1999;8:599-605.

13. Keener JD, Steger-May K, Stobbs G, Yamaguchi K. Asymptomatic rotator cuff tears: patient demographics and baseline shoulder function. J Shoulder Elbow Surg 2010;19:1191-8.

14. Minagawa H, Yamamoto N, Abe H, et al. Prevalence of symptomatic and asymptomatic rotator cuff tears in the general population: from mass-screening in one village. J Orthop 2013;10:8-12.

15. Yamamoto A, Takagishi K, Kobayashi T, Shitara H, Osawa T. Factors involved in the presence of symptoms associated with rotator cuff tears: a comparison of asymptomatic and symptomatic rotator cuff tears in the general population. J Shoulder Elbow Surg 2011;20:1133-7.

16. Sørensen AK, Bak K, Krarup AL, et al. Acute rotator cuff tear: do we miss the early diagnosis?: a prospective study showing a high incidence of rotator cuff tears after shoulder trauma. J Shoulder Elbow Surg 2007;16:174-80.

17. Neviaser RJ, Neviaser TJ, Neviaser JS. Concurrent rupture of the rotator cuff and anterior dislocation of the shoulder in the older patient. J Bone Joint Surg Am 1988;70:1308-11.

18. Loew M, Porschke FB, Riedmann S, Magosch P, Lichtenberg S. Zur Unterscheidung zwischen traumatischer und degenerativer Rotatorenmanschettenruptur: eine klinische und radiologische Untersuchung. Obere Extremität 2014;9:209-14.

19. Loew M, Magosch P, Lichtenberg S, Habermeyer P, Porschke F. How to discriminate between acute traumatic and chronic degenerative rotator cuff lesions: an analysis of specific criteria on radiography and magnetic resonance imaging. J Shoulder Elbow Surg 2015;24:1685-93.

20. Balich SM, Sheley RC, Brown TR, Sauser DD, Quinn SF. MR imaging of the rotator cuff tendon: interobserver agreement and analysis of interpretive errors. Radiology 1997;204:191-4.

21. Owen RS, Iannotti JP, Kneeland JB, Dalinka MK, Deren JA, Oleaga L. Shoulder after surgery: MR imaging with surgical validation. Radiology 1993;186:443-7.

22. Zanetti M, Jost B, Hodler J, Gerber C. MR imaging after rotator cuff repair: full-thickness defects and bursitis-like subacromial abnormalities in asymptomatic subjects. Skeletal Radiol 2000;29:314-9.

23. Goutallier D, Postel JM, Bernageau J, Lavau L, Voisin MC. Fatty muscle degeneration in cuff ruptures: pre- and postoperative evaluation by CT scan. Clin Orthop Relat Res 1994;(304):78-83.

24. Hantes ME, Karidakis GK, Vlychou M, Varitimidis S, Dailiana Z, Malizos KN. A comparison of early versus delayed repair of traumatic rotator cuff tears. Knee Surg Sports Traumatol Arthrosc 2011;19:1766-70.

25. Yamaguchi K, Ditsios K, Middleton WD, Hildebolt CF, Galatz LM, Teefey SA. The demographic and morphological features of rotator cuff disease: a comparison of asymptomatic and symptomatic shoulders. J Bone Joint Surg Am 2006;88:1699704.

26. Yamaguchi K, Tetro AM, Blam O, Evanoff BA, Teefey SA, Middleton WD. Natural history of asymptomatic rotator cuff tears: a longitudinal analysis of asymptomatic tears detected sonographically. J Shoulder Elbow Surg 2001;10:199-203.

27. Inman VT, Saunders JB, Abbott LC. Observations on the function of the shoulder joint. J Bone Joint Surg 1944;26:1-30.

28. Walch G, Edwards TB, Boulahia A, Nové-Josserand L, Neyton L, Szabo I. Arthroscopic tenotomy of the long head of the biceps in the treatment of rotator cuff tears: clinical and radiographic results of 307 cases. J Shoulder Elbow Surg 2005;14:238-46.

29. Park JS, Park HJ, Kim SH, Oh JH. Prognostic factors affecting 
rotator cuff healing after arthroscopic repair in small to medium-sized tears. Am J Sports Med 2015;43:2386-92.

30. Hsu HC, Luo ZP, Cofield RH, An KN. Influence of rotator cuff tearing on glenohumeral stability. J Shoulder Elbow Surg 1997;6:413-22.

31. Pouliart N, Gagey O. Concomitant rotator cuff and capsuloligamentous lesions of the shoulder: a cadaver study. Arthroscopy 2006;22:728-35.

32. Sonnabend DH. Treatment of primary anterior shoulder dislocation in patients older than 40 years of age: conservative versus operative. Clin Orthop Relat Res 1994;(304):74-7.

33. Simank HG, Dauer G, Schneider S, Loew M. Incidence of rotator cuff tears in shoulder dislocations and results of therapy in older patients. Arch Orthop Trauma Surg 2006;126:235-40.

34. Melis B, Wall B, Walch G. Natural history of infraspinatus fatty infiltration in rotator cuff tears. J Shoulder Elbow Surg 2010; 19:757-63.
35. Gimbel JA, van Kleunen JP, Lake SP, Williams GR, Soslowsky LJ. The role of repair tension on tendon to bone healing in an animal model of chronic rotator cuff tears. J Biomech 2007; 40:561-8.

36. Gimbel JA, van Kleunen JP, Mehta S, Perry SM, Williams GR, Soslowsky LJ. Supraspinatus tendon organizational and mechanical properties in a chronic rotator cuff tear animal model. J Biomech 2004;37:739-49.

37. Barton ER, Gimbel JA, Williams GR, Soslowsky LJ. Rat supraspinatus muscle atrophy after tendon detachment. J Orthop Res 2005;23:259-65.

38. Hersche O, Gerber C. Passive tension in the supraspinatus musculotendinous unit after long-standing rupture of its tendon: a preliminary report. J Shoulder Elbow Surg 1998;7:393-6.

39. Iannotti JP. The rotator cuff: current concepts and complex problems. Rosemont, IL: American Academy of Orthopaedic Surgeons; 1998. 